\title{
DOE/BNL Liquid Natural Gas Heavy Vehicle Program
}

James E. Wegrzyn and Wai-Lin Litzke

Brookhaven National Laboratory

Michael Gurevich

U.S. Department of Energy 
The appearance of the ISSN codeat the bottom of this page indicates SAE's consent that copies of the papermaybemadefor personal orintemaluse of specific clients. Thisconsent is given on the condition however, that the copierpay a $\$ 7.00$ perarticle copyfeethrough the Copyright Clearance Center, Inc. Operations Center, 222 Rosewood Drive, Danvers, MA 01923 forcopying beyond thatpermitted by Sections 107 or 108 of the U.S. Copyright Law. This consent does not extend to other kinds of copyingsuch as copying for general distribution, for advertising orpromotional purposes, forcreating newcollective works, or forresale.

SAE routinely stocks printed papers for a period of three years following date of publication. Directyourordersto SAECustomerSales andSatisfaction Department.

Quantity reprint ratescan be obtainedfrom the CustomerSales andSatisfaction Department.

To requestpermissionto reprint atechnical paperorpermission to use copyrightedSAE publications in otherworks, contact the SAE Publications Group.

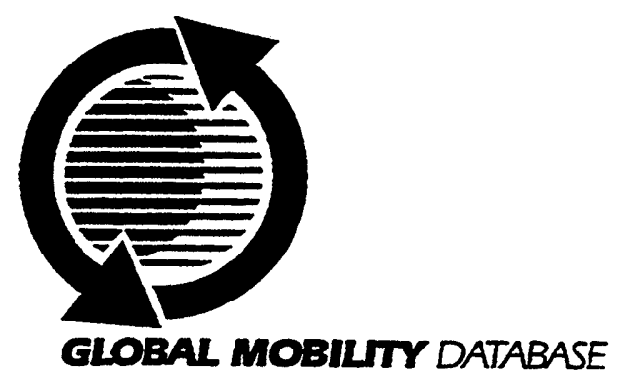

All SAE papers, standards, and selected booksareabstractedandindexedinthe SAE GlobalMobility Database.

Nopart of thispublication may by reproduced in anyform, in an electronic retrievalsystem or otherwise, without the priorwritten permission of the publisher.

\section{ISSN0148-7191}

Copyright 1998 Society of Automotive Engineers, Inc.

Positions and opinionsadvancedinthispaperarethose of theauthor(s) and notnecessarity those of SAE The authorissolely responsible for the content of the paper. A process is available by which discussions will be printed with the paper if it is published in SAE Transactions. For permission to publish this paper in full or in part, contact the SAE Publications Group.

Persons wishing tosubmitpapersto be consideredforpresentation orpublication through SAE should send the manuscript or a 300 word abstract of a proposed manuscript to: Secretary, Engineering Meetings Board, SAE. 


\title{
DOE/BNL Liquid Natural Gas Heavy Vehicle Program
}

\author{
James E. Wegrzyn and Wai-Lin Litzke \\ Brookhaven National Laboratory \\ Michael Gurevich \\ U.S. Department of Energy
}

Copyright (c) 1998 Society of Automotive Engineers, Inc.

\begin{abstract}
As a means of lowering greenhouse gas emissions, increasing economic growth, and reducing the dependency on imported oil, the Department of Energy and Brookhaven National Laboratory (DOE/ BNL) is promoting the substitution of liquefied natural gas (LNG) in heavyvehicles that are currently being fueled by diesel. Heavy vehicles are defined as Class $7 \& 8$ trucks $(>118,000$ pounds GWW), and transit buses that have a fuel usage greater than 10,000 gallons per year and driving range of more than 300 miles. The key in making LNG marketcompetitive with all types of diesel fuels is in improving energy efficiency and reducing costs of LNG technologies through systems integration. This paper integrates together the three LNG technologies of: (1) production from landfills and remote well sites; (2) cryogenic fuel delivery systems; and (3) state-of-the-art storage tank and refueling facilities, with market end-use strategies. The program's goal is to develop these technologies and strategies under a "green" and "clean" strategy. This "green" approach reduces the net contribution of global warming gases by reducing levels of methane and carbon dioxide released by heavy vehicles usage to below recoverable amounts of natural gas from landfills and other natural resources. Clean technology refers to efficient use of energy with low environmental emissions. The objective of the program is to promote fuel competition by having LNG priced between $\$ 0.40-\$ 0.50$ per gallon with a combined production, fuel delivery and engine systems efficiency approaching $45 \%$. This can make $L N G$ a viable alternative to diesel.
\end{abstract}

\section{INTRODUCTION}

Since 1973 essentially all of the increase in U.S. highway fuel consumption has been due to trucks [1]. Furthermore, it has been projected that by the year 2020 the energy use for mid to heavy-duty trucks (Class 3-8) can amount to about 2 million barrels per day. Great strides can be made in terms of environmental impact, national security and economic growth if even $10 \%$ of this transportation energy from diesel fuel can be converted to LNG. LNG is the alternative fuel of choice for heavy vehicles because in comparison to other alternative fuels LNG has the advantages of low engine emissions, lower fuel costs, and greater reserves.

Use of natural gas is expected to increase steadily in the U.S. over the next 20 years, from 22 tcf/year in 1997 to over 30 tcf/yr by 2010 . Some estimates call for even higher levels, $40 \mathrm{tcf} / \mathrm{yr}$, if initiatives in support of reduced emissions of greenhouse gases is considered. One of the fastest growing sources of new gas supplies is "unconventional gas" - tight gas sands, gas shales, and coalbed methane, with total projected production rate to amount to about 6 tcf/yr [2]. The underlying resource base for natural gas is vast, though still largely undefined and unproductive with today's technology and prices. The utilization of these future gas supplies depends greatly on research investments.

Some of the main decision drivers that will allow LNG to penetrate and sustain the market include user acceptability, environmental benefits, economic incentives, fuel/ technology availability, and infrastructure. Other important issues include codes and permitting for siting fueling stations, vehicle maintenance, safety and training issues. The scope of the DOE/ BNL program addresses these major issues so that the LNG product can overcome existing market barriers and become a viable, economical, and clean alternative fuel.

\section{NATURAL GAS UTILIZATION OPTIONS FOR HEAVY VEHICLES}

There are available various options to harness energy from natural gas. These include gas to liquid, gas to wire, and gas to CNG/ LNG. The energy efficiencies associated with processing, extraction, production, transport, conversion and refining have been studied [3] to yield an overall fuel 
processing efficiency. Only the chemical conversion and mechanical work distribution efficiencies have been considered in this paper to simplify the analysis.

Overall program goals are established by taking the First Law of Thermodynamics with several simplifying assumptions to determine the energy losses when converting methane to other transportation liquid fuels, electricity, and CNG/ LNG. The First Law of Thermodynamics states that heat $(Q)$ is equal to the change in internal energy $\left(U_{2}-U_{1}\right)$ plus work $(W)$ or:

$$
\Delta Q=\left(U_{2}-U_{1}\right)+\Delta W
$$

Natural gas has a heating value of $Q=-890 \mathrm{~kJ} /$ mole. The initial assumptions being made are: (1) for gas to liquid fuels conversion, the heat of formation $\left(U_{2}-U_{1}\right)>>W$; and (2) for gas to $L N G, C N G$ and electricity $W>>\left(U_{2}-U_{1}\right)$. In other words, for gas to liquid it is assumed that the chemical conversion represents the major energy loss. For gas to CNG/LNG and gas to wire the mechanical work dominates. These energy losses are illustrated in Figures 1 and 2.

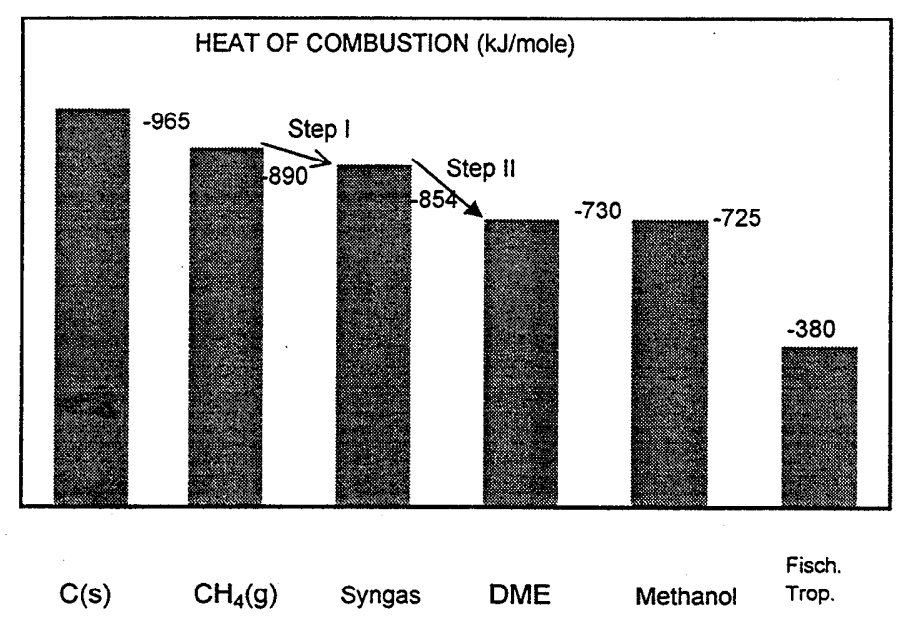

Figure 1. Heating values for various alternative liquid fuels

Figure 1 shows the heat of combustion for the various fuels. A two-step process is indicated by the arrows where step I gives syngas production, and step II syngas transformation to methanol, dimethyl ether, and FischerTropsch diesel. This is necessary because direct synthesis from natural gas is not commercially available. These values are determined from the following chemical reactions:

\section{Well-Site usage}

$\mathrm{CH}_{4(g)}+2 \mathrm{O}_{2} \Rightarrow \mathrm{CO}_{2(g)}+2 \mathrm{H}_{2} \mathrm{O}_{(\eta)} \quad \Delta \mathrm{H}_{\mathrm{c}}=-890 \mathrm{~kJ} / \mathrm{mole}$

where $\Delta H_{c}$ is the heat of combustion.

Direct methane to liquids is not considered since this process is not expected to be available in the near future. A conventional two-step process involves syngas production (Step I) and then syngas transformations (Step

II) that yields hydrocarbon and oxygenated products. The fuels considered in this study are Fischer-Tropsch diesel (F-T), methanol (MeOH) and dimethyl ether (DME). DME is essentially derived from methanol by dehydration [4].

Syngas Production (Step I)

$$
\begin{array}{ll}
\mathrm{CH}_{4(\mathrm{~g})}+1 / 2 \mathrm{O}_{2} \Rightarrow \mathrm{CO}+2 \mathrm{H}_{2} & \Delta \mathrm{H}_{\mathrm{r}}=-36 \mathrm{~kJ} / \mathrm{mole} \\
\mathrm{CO}+2 \mathrm{H}_{2}+3 / 2 \mathrm{O}_{2} \Rightarrow \mathrm{CO}_{2}+2 \mathrm{H}_{2} \mathrm{O} & \Delta \mathrm{H}_{\mathrm{c}}=-854 \mathrm{~kJ} / \mathrm{mole}
\end{array}
$$

\section{Syngas Transformation (Step II)}

1. Methanol Synthesis

$$
\begin{array}{lll}
\mathrm{CO}+2 \mathrm{H}_{2} \Rightarrow \mathrm{CH}_{3} \mathrm{OH} & \Delta \mathrm{H}_{\mathrm{r}}=-165 \mathrm{~kJ} / \mathrm{mole} \\
\mathrm{CH}_{3} \mathrm{OH}+3 / 2 \mathrm{O}_{2} \Rightarrow \mathrm{CO} 2+2 \mathrm{H}_{2} \mathrm{O} & \Delta \mathrm{H}_{\mathrm{c}}=-725 \mathrm{~kJ} / \mathrm{mole}
\end{array}
$$

2. Dimethyl Ether Synthesis

$$
\begin{array}{ll}
\mathrm{CO}+2 \mathrm{H}_{2} \Rightarrow 1 / 2\left(\mathrm{CH}_{3}\right)_{2} \mathrm{O}+1 / 2 \mathrm{H}_{2} \mathrm{O} & \Delta \mathrm{H}_{\mathrm{r}}=-160 \mathrm{~kJ} / \mathrm{mole} \\
1 / 2\left(\mathrm{CH}_{3}\right)_{2} \mathrm{O}+3 / 2 \mathrm{O}_{2}=\mathrm{CO}_{2}+3 / 2 \mathrm{H}_{2} \mathrm{O} & \Delta \mathrm{H}_{\mathrm{c}}=-730 \mathrm{~kJ} / \mathrm{mole}
\end{array}
$$

The heat of combustion of a mole of dimethyl ether is $1460 \mathrm{~kJ}$. Since it takes 2 moles of methane to make

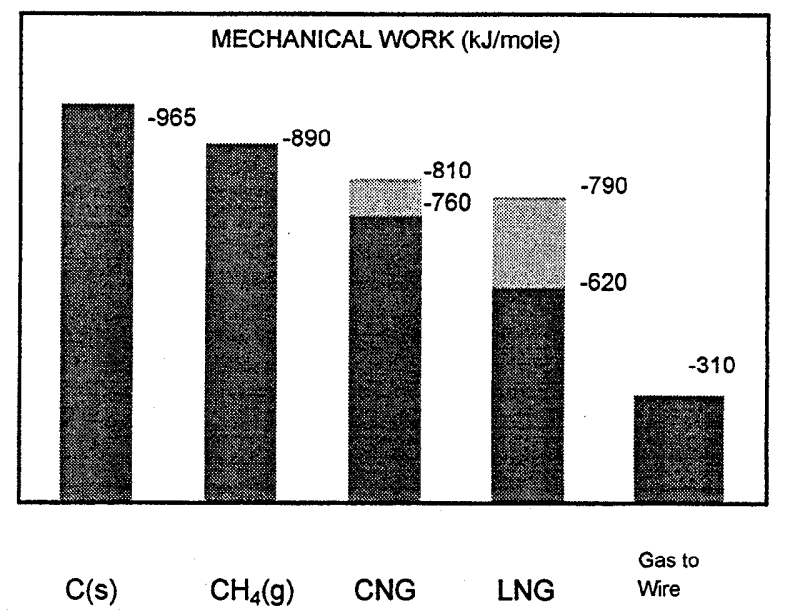

Figure 2. Mechanical work of distribution

dimethyl ether the heat of combustion of DME normalized to a mole of methane is $-730 \mathrm{~kJ}$.

3. Hydrocarbon Synthesis (Fischer-Tropsch process)

$$
\begin{array}{r}
\mathrm{CO}+2 \mathrm{H}_{2} \Rightarrow 2 / 49\left[\mathrm{H}-\left(-\mathrm{CH}_{2}-\right)_{16}-\mathrm{H}+32 \mathrm{H}_{2} \mathrm{O}+17 / 2 \mathrm{CO}_{2}\right] \\
\Delta \mathrm{H}_{\mathrm{r}}=-510 \mathrm{~kJ} / \mathrm{mole} \\
2 / 49\left[\mathrm{H}-\left(-\mathrm{CH}_{2}-\right)_{16}-\mathrm{H}\right]+\mathrm{O}_{2} \Rightarrow \begin{array}{c}
32 / 49 \mathrm{CO}_{2}+34 / 49 \mathrm{H}_{2} \mathrm{O} \\
\Delta \mathrm{H}_{\mathrm{c}}=-380 \mathrm{~kJ} / \mathrm{mole}
\end{array}
\end{array}
$$




\section{PROGRAM OVERVIEW}

The above equation shows that syngas from partial oxydation of one mole of methane yields $2 / 49$ moles of F-T diesel. The heat of combustion of one mole of diesel was taken to be $-9500 \mathrm{~kJ} / \mathrm{mole}$.

Converting methane to CNG or LNG requires mechanical work to compress or liquefy, respectively. The energy needed depends on the efficiency of the process; for compression and liquefaction this is estimated to be roughly $30-50 \%\left(\epsilon_{c}\right)$ and $15-40 \%\left(\epsilon_{l}\right)$ respectively. Each of these processes are considered below. The efficiency to convert methane to electricity is considered to be $35 \%\left(\epsilon_{w}\right)$.

The minimum energy required to liquefy natural gas is given by the equation,

$$
Q_{l, \min }=W_{l, \min }=C p \Delta T+\Delta H_{v}
$$

where $\mathrm{C}_{\mathrm{p}}=2.093 \mathrm{~J} / \mathrm{g}-{ }^{\circ} \mathrm{C}$, the specific heat of gas at constant pressure and $\Delta \mathrm{H}_{v}=502 \mathrm{~J} / \mathrm{g}$, the latent heat of vaporization.

To liquefy natural gas from $20^{\circ} \mathrm{C}$ to $-160^{\circ} \mathrm{C}$ requires 14.1 $\mathrm{kJ} /$ mole. The actual work required is determined by the following equation:

$$
\begin{aligned}
& W_{l}=W_{l, \text { min }} /\left(\epsilon_{w}\right)\left(\epsilon_{l}\right) \\
& 100=14.1 /(0.35)(0.4)<W_{l}<14.1 /(0.35)(0.15)=270
\end{aligned}
$$

Depending on the efficiency of the process to produce LNG the amount of available energy is roughly $620-790 \mathrm{~kJ}$. This is comparable to the energy value of $\mathrm{MeOH}$ and DME. A barrier to using $\mathrm{MeOH}$ is the corrosive nature of the fuel and the consideration for compatibility of materials used in fuel storage and fuel transfer systems [5]. One advantage DME has over LNG is that it has infrastructure requirements similar to propane, that is low storage pressure at room temperature (less than $100 \mathrm{psi}$ ).

The minimum amount of energy to isothermally compress natural gas is:

$$
\begin{aligned}
Q_{c, \min }=W_{c, \min }=R T \ln \left(p_{2} / p_{1}\right) & =(8.32)(300 \mathrm{~K}) \ln (3600 / 14.7) \\
& =13.7 \mathrm{~kJ} / \mathrm{mole}
\end{aligned}
$$

$\mathrm{W}_{\mathrm{c}}=\mathrm{W}_{\mathrm{c}, \min } /\left(\epsilon_{w}\right)\left(\epsilon_{c}\right)$

$130=13.7 /(0.35)(0.3)<W_{c}<13.7 /(0.35)(0.5)=78$

The total amount of work needed to compress natural gas to $3600 \mathrm{psi}$ is less than that needed to liquefy, but the cost of the compressors and its limited onboard storage capacity (which equates to driving range), make this a less attractive option as compared to LNG.
Figure 3 shows an overview of the DOE/BNL work in fuel production, fuel delivery systems, storage, and market/enduse strategies. The approach is to improve overall energy efficiency and life-cycle costs through innovative research and systems integration. Under DOE's Office of Energy Efficiency and Renewable Energy, multi-year heavy vehicle program subcontracts are being placed to work in these specific areas.

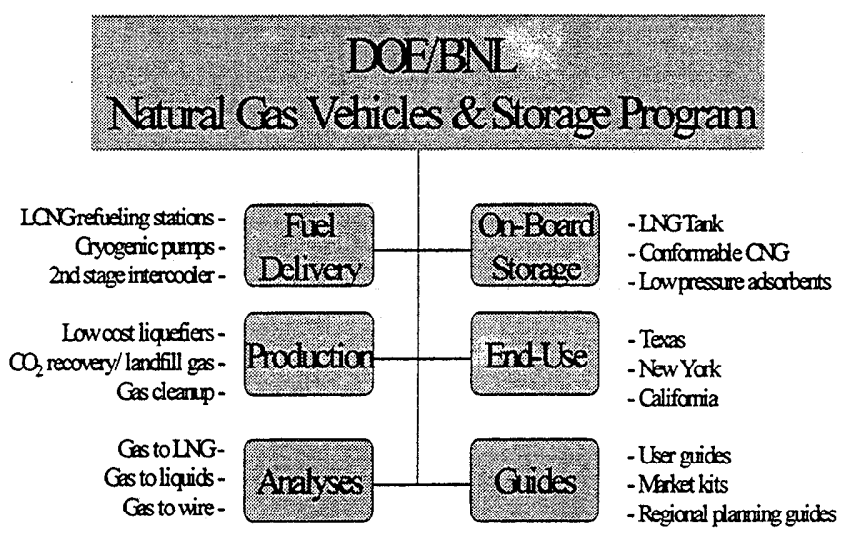

Figure 3. Overview of DOE/BNL work

The program goal is to achieve a $5 \%$ improvement of overall system efficiency by eliminating boil-off, improving the onboard gas delivery system, and improving production efficiency. This $5 \%$ energy efficiency improvement is in addition to DOE's other program that focuses on raising the thermal efficiency of natural gas engines from $30 \%$ to $50 \%$. Since LNG is stored and transported under cryogenic conditions, up to $3 \%$ of the LNG can be released directly to the atmosphere as boil-off gas. Depending on the storage vessel and range that bulk LNG is transported, some venting is required as the liquid warms and vaporizes to prevent excessive pressure buildup. LNG stored onboard can also contribute to boil-off depending on the vehicle's duty cycle and fuel delivery system. Not only do these releases impact environmental emissions but they also become real storage and safety issues that must be addressed.

Currently, it is estimated that $10-30 \%$ of the energy value of natural gas ( $890 \mathrm{~kJ} / \mathrm{mole})$ is required to make LNG. Largescale liquefaction plants are generally more efficient [6]. The greatest potential for improved efficiency is in the development of improved, low-cost small-scale liquefiers. These small liquefiers are essential to providing and expanding an infrastructure for the supply of LNG for heavy vehicle use from landfill gas, coal mines, and capped oil wells. These stranded sources of gas are not currently accessible through the pipeline. Fleet vehicles are the current target market for such fuels.

In addition to energy efficiency improvements the program also targets a reduction of life-cycle costs by $25 \%$. A recent 
comparison of new natural gas buses versus "clean" diesel buses indicates that LNG costs are about $18 \%$ higher [7].

Life cycle costs consider the price of vehicle purchase/ engine replacement (incremental cost), fuel cost, fueling station construction and operating costs, and maintenance costs. Opportunities for savings are with incremental vehicle costs, fuel, and refueling station costs. The objectives are to provide a competitive and stable fuel price of about $\$ 0.40$ per gallon, and improve the infrastructure. Currently, LNG prices across the U.S. range from about $\$ 0.40$ to $\$ 0.60$ per gallon.

As illustrated in Figure $3 \mathrm{DOE} / \mathrm{BNL}$ is supporting and funding the following areas of study to achieve these goals:

PRODUCTION - Cryogenic liquefiers are commercially available for liquefaction of natural gas, but with the current market these are profitable for only large scale capacities. To date, the natural gas vehicle market has not generated enough demand to develop a low-cost liquefier. The developing market and technology for NGVs however, provide a new opportunity for considering LNG fueling concepts requiring lower liqefaction installed facility costs. The recent growth in LNG demonstration programs and dedicated LNG fueled fleets has created a market demand for small shop-assembled liquefier in the 3,000 gallon per day capacity range.

DOE/BNL is funding the development of a novel natural gas liquefaction system that will use mass produced refrigeration compressor technology. The use of this "off-the-shelf" low cost technology is further enhanced by developing new refrigerant mixtures. The specific objectives of this work are to demonstrate the technical feasibility of the proposed refrigerant with reduced installation, operation and maintenance costs. The unique characteristics of mixed refrigerants, used in conventional refrigeration for LNG liquefaction, allows for lower system pressures and better thermal management., leading to a simpler system configuration. Under this project an experimental LNG liquefier having a capacity of 300 gal/day will be developed for concept testing. The capacity would be readily expandable by at least a factor of 10 .

The use of large and relatively new landfills that serve major metropolitan areas as a source for natural gas can be an effective means of displacing some of the energy consumed by fleet vehicles currently using diesel. Landfill gas generated by decomposing refuse typically contains $50 \%$ methane, and $50 \% \mathrm{CO} 2$ with trace contaminants (other than nitrogen and water, up to $1 \%$, ie. mostly containing chlorine and sulfur). Unrecovered methane is usually collected and flared to prevent subsurface migration, to convert methane to $\mathrm{CO} 2$ (less potent greenhouse gas), and to destroy (oxidize) contaminants. Methane vented from existing U.S. landfills is estimated to equal about $5 \%$ of domestic natural gas consumption, or $1 \%$ of domestic total energy needs. This raw gas is largely wasted resource that could provide locally significant supplemental energy.
DOE/ BNL is funding a feasibility study on the production of $L N G$ and liquid carbon dioxide ( $\mathrm{CO} 2$ ) from landfill gas. The scope of work involves designing a process that will use in-situ CO2 wash technology to produce about 16,000 gal/day of LNG and 70 tons/day of liquid CO2 from 4 million standard cubic feet per day of raw landfill gas (LFG). This process removes contaminants from LFG using in-situ liquid carobn dioxide condensed from the LFG. A contaminant free stream containing $80 \%$ methane (with any nitrogen present) and $20 \% \mathrm{CO} 2$ is produced along with a concentrated stream of contaminants in $\mathrm{CO} 2$. The stream enriched in methane is further processed to remove the remaining $\mathrm{CO} 2$ and then liquefied for vehicle fuel. Integration of these low temperature processes, $\mathrm{CO} 2$ wash and methane liquefaction, will be investigated to reduce overall costs. Future plans include analyses of local markets for LNG and liquid CO2 produced, sales, refuse truck conversion and fueling stations, and full scale demonstration.

STORAGE - DOE/BNL is funding a project to advance the technology of LNG storage tanks through product improvements and extensive testing. The tanks being developed provide low pressure storage (20-50 psig). Some of the advantages of low pressure system include: minimum venting and weathering of LNG; increased "no vent" standby time of the LNG tank; lower cost of fueling equipment, installation operation, and maintenance; improved reliability and safety during fueling operations. During fueling, the saturated vapor in the vapor space is vented as liquid volume replaces vapor volume. Low vent rates during fueling can allow for economical reliquefaction recovery. Reduced venting and longer standby time (during when vehicle is not operating) means less boil-off. Low pressure also allows for easier control of engine air/fuel ratios and maintaining fuel temperatures. These tanks will incorporate improved insulation while minimizing weight, lower manufacturing costs, improvement of the pressure relief system, automatic fueling shut-off, and low-cost quantity gauging system. Another reason for funding this project is to promote competition by provide an incentive for this smaller tank manufacturer to enter the market.

FUEL DELIVERY AND INFRASTRUCTURE - DOE/ BNL is interested in a plan for a full-scale demonstration of advanced LCNG fueling facilities (capable of fueling both LNG and CNG vehicles) in Dallas, Texas. The refueling station will service a fleet of heavy-duty LNG vehicles to be operated by the U.S. Postal Service (USPS) in Texas. This effort is currently being led by the Texas General Land Office to develop a network of alternative fuel stations throughout Texas and the Southwest, located along major clean corridors of the region. It consists of a partnership of Federal, State and local agencies, private fleet operators, vehicle/ engine manufacturers, fuel suppliers and the North American Superhighway Coalition. The purpose of this broad effort is to promote the use of clean fuels in local and long-distance fleets along major Interstate Highways in Texas and surrounding states. 
The fleet consists of 123 vehicles with the most advanced LNG heavy-duty engines with emissions that meet ULEV levels while delivering sufficient power and good driveability. The on-board LNG fuel systems will incorporate design features that will allow lower operating pressures which will extend hold time and minimize release of boil-off. These heavy-duty LNG vehicles will displace about 720,000 gallons of diesel fuel per year, and reduce air emissions in the Dallas area by about 40 tons per year.

The availability of conveniently located fueling facilities will remove the most significant barrier to the conversion of these fleets to LNG and CNG operations. This study will look at the design, operating experience, and economics of the LCNG facillities and will provide recommendations as to how to make future LCNG fueling facilities more user friendly, reliable, and cost-effective. It will also document the operating experience, economics, and emissions of the heavy-duty LNG vehicles.

High efficiency, low-emissions natural gas engines are being developed that require high pressure feed of LNG at up to 3600 psi. However, for on-board vehicle systems it is desirable to store LNG at low pressure. To raise the pressure to engine requirements a cryogenic pump is needed. DOE/BNL is supporting the development and testing of a novel on-board cryogenic pump for heavy vehicles. This pump is designed for low heat leaks and vapor formation, no LNG leakage, and is relatively insensitive to cavitation as compared to current cryogenic pumps.

DOE/BNL is also funding a project to add LCNG capability to an existing LNG refueling station that is unique in that its storage tank is buried underground. The work specifically includes designing, modifying and installing an existing high pressure cryogenic pump along with other CNG related hardware. The pump will be submersed in an underground sump sharing a common insulating vessel with the storage tank. This underground approach to storage, piping and containment provides an added measure of safety, and aesthetics. This LNG fueling station incorporates technology that reduces initial capital, as well as operating costs, and is considered one of the most transparent to traditional gasoline and diesel stations.

END-USE - DOE/BNL is participating in an international collaboration based in California, that will conduct a feasibility study of converting to LNG fuel the 18-wheeled trucks that ship products to and from California's seaports. This project aims to introduce LNG to the market while also addressing local residents' concerns over particulate emissions from diesel-powered trucks. Seaports are major economic engines in the communities/regions in which they are located and that they serve. The potential impact of incorporating LNG as a transportation fuel in port-related trucking activities continues to grow as United States ports increase the amount of goods imported and exported. Currently, the Port of Los Angeles generates more than one million truck trips annually, and it is predicted that there will be a doubling of cargo by 2020 . From this study a report will be produced that will detail economic and environmental costs and benefits of $L N G$, siting of infrastructure installations, fuel pricing, non-direct economic benefits (such a public relations value), and barriers to LNG use. These elements are critical to the planning and decision-making process of the port authorities, regional planning groups, and transportation companies regarding the viability of LNG as a transportation fuel.

Future work planned involving the ports include siting of the small-scale liquefier developed under this DOE/BNL program and possibly support demonstration projects at the ports.

DOE/ BNL is partnering with Gas Research Institute to cost-share three projects. The aim of these projects is to address the market barriers that prevent widespread use of LNG as a transportation fuel and "end-use" needs.

They comprise mainly of user guides and marketing kits for the promotion of LNG in heavy-duty vehicle use. These projects will identify planning, zoning, code enforcement, permitting, and startup issues with the installation of new LNG/ LCNG fueling stations. This information is needed by city agencies, regulators, administrators, fleet owners and operators who have a role in the location and use of the fueling stations.

\section{IMPROVED AIR QUALITYIECONOMIC INCENTIVES}

For areas federally classified as "nonattainment" for ozone, reducing NOx emissions, a precursor to ozone, is required. A large part of the NOx comes from heavy-duty vehicles. In California, an aggressive program using market based incentive programs is being implemented to convert to lowemission, heavy vehicles in local fleets [8].

Current natural gas engines are of the spark-ignition or the dual fuel (natural gas with diesel pilot ignition) type. Both can significantly reduce NOx and carbon monoxide, by as much as $50 \%$ for these contaminants. One advantage of the dual fuel natural gas engine is that its performance, fuel consumption versus engine load, closely matches that of diesel. Natural gas engines can comply with the stringent 1998 ultra low emission vehicle (ULEV) standards for heavy-duty vehicles. The natural gas engine can reduce the NOx emissions by $50 \%$ compared to diesel engine emissions, and meet the strict NOx limits.

Federal and state government incentives towards using cleaner, domestic fuels, are critical to overcoming the economic hurdles and building the fuel supply infrastructure. A sustainable maket for LNGVs depends largely on the current price of oil. With the cost of oil at less than $\$ 20$ per barrel, LNG usage may not be economically attractive without monetary incentives. The Taxpayer Relief Act which sets the federal excise tax allows for about a four cents advantage for for LNG (\$ 
0.202 per diesel-gallon equivalent) over diesel which is currently at $\$ 0.244$ per gallon. To make LNGV's more attractive government funding in the form of payment for air quality improvement may be needed. California's vigorous efforts to attain air quality standards have led to proposed legislation or exisiting financial incentive programs specific to the various air quality districts. As an example, the San Joaquin Valley Unified Air Pollution Control District utilizes California Department of Motor Vehicles Surcharge Fees to generate funds for alternative fuel projects. Credit is provided to off-set the differential cost associated with purchasing low-emission technology. To illustrate the potential savings, consider an allowance of $\$ 12,000$ per ton of NOx reduced for on-road vehicles [9]. It has been reported that the 123 heavy duty LNG vehicles operated by the U.S. Postal Service in Texas can reduce air emissions in the Dallas area by about 40 tons per year. Assuming that $20 \%$ of this is attributed to NOx this equates to about $\$ 96,000$. In another case, an estimate done by the Maryland Mass Transit Administration showed that with a 240-bus fleet, and buses operating 30,000 miles per year, exhaust emissions could be reduced by over 100 tons per year operating on LNG [10].

Representative John Ensign (R-NV) is ready to introduce a bill that would grant fleet operators and other vehicle operators a tax break for using alternative fuels. Ensign's bill, which would create a 50-cent-per-gallon-equivalent break, has support from natural gas and propane vehicle proponents.

\section{“GREEN" TECHNOLOGY}

Technologies associated with the production of LNG from natural resources (such as landfill gas, coal mines) can be promoted as "green," as a result of reducing net greenhouse gas emissions, and prompt federal funding or incentives thus making this local source of fuel an economically feasible option. In this case, net reduction of global warming gases means that more natural gas can be recovered from landfill than the amount released to the atmosphere by the use of LNG.

LNG vehicles should have the same exhaust emissions as CNG vehicles except that LNG vehicles may require venting of methane from the fuel storage system. This contributes to the overall greenhouse gas emissions and this storage issue is a major concern. If LNG vehicles are used regularly venting may not be needed. However, if LNG vehicle is left idle for more than a week, venting becomes necessary to prevent excessive pressure in fuel tanks. Approximately 0.5 to $3 \%$ of the total energy is attributed to boil-off from vehicles and bulk storage. LNG from landfill gas can be used to offset releases from boiloff.

To illustrate the feasibility of LFG to offset boil-off let's assume that $10 \%$ of the energy used by heavy-duty trucks is in the form of LNG which amounts to 0.2 million barrels of oil per day. If $1 \%$ of this is lost to boil-off during storage this is equivalent to about $12,000 \mathrm{MMBtu} /$ day. The amount of landfill gas generated by a municipal landfill is significant; 5 million standard cubic feet per day (MMSCF/day) is a conservative estimate for a large landfill typical of those found in or near all large metropolitan areas of the United States. For this example, an average of $2 \mathrm{MMSCF} /$ day is used. A gas-phase wash technology using existing carbon dioxide from the landfill can be used to effectively remove contaminants from LFG and recover liquid $\mathrm{CO} 2$ simultaneously. This process can be designed to recover about 4,500 gallons of liquid methane for each MMSCF of raw landfill gas fed to the plant ( $55 \%$ methane content). This would generate about $650 \mathrm{MMBtu}$ landfill per day which would require that roughly 19 large landfills be converted to offset all the boil-off released to the atmosphere. Also, there is the added benefit of recovering useable $\mathrm{CO} 2$.

In general, because of geographic and economic hurdles conversion of landfill gas (LFG) may not be a likely major feedstock source, nor significantly reduce overall greenhouse emission.

\section{CONCLUSION}

This paper compared LNG technology with other alternatively liquid fuels derived from natural gas. For LNG to be market-competitive with diesel fuel there are specific technical and nontechnical barriers that clearly need to be addressed. The industry needs low-cost, high efficiency, small-scale liquefiers (size range), fuel delivery systems with no boil-off gases, user-friendly refueling stations, and a disperse infrastructure (remote gas well-sites, landfill gas) where economically feasible and centralized pipeline gas is not available. Government programs need to provide incentives until market matures and infrastructure is developed to promote all technologies, competition among manufacturers, and "green" technologies to ensure a viable, low cost alternative fuel with reduced emissions.

\section{ACKNOWLEDGMENTS}

This work was done under contract no. DE-ACO2$98 \mathrm{CH} 10886$ with the United States Department of Energy.

\section{REFERENCES}

[1] OHVT Technology Roadmap, Office of Heavy Vehicle Technologies/ Office of Transportation Technology, Report No. DOE/OSTI-11690, October 1997.

[2] Kuuskraa, Vello A., "Outlook bright for U.S. natural gas resources," Oil \& Gas Journal, April 13, 1998.

[3] Stodolsky, Frank and Santini, Danilo J., "Fueling up with natural gas," CHEMTECH, October 1993. 
[4] Hansen, John B., et.al., "Large Scale Manufacture of Dimethyl Ether - a New Alternative Diesel Fuel from Natural Gas," SAE Paper 950063.

[5] Bechtold, Richard L., Alternative Fuels Guidebook, Society of Automotive Engineers, 1997.

[6] "Chiyoda Develops More Efficient Natural Gas Liquefaction Process," Remote Gas Strategies, p.12, Vol. II, No. 5, May 1998.

[7] Kucera, Larry, "Overview of Valley Metro, Phoenix Regional Public Transportation Authority," LNG: Prospecting Downstream Markets, Colorado Springs, CO, March 23-25, 1998.

[8] Taylor, Timothy W., "Overview of Sacramento Metropolitan Air Quality Management Districts Heavy- Duty Alternative Fuel Program," Conference on LNG: Prospecting Downstream Markets, Colorado Springs, CO, March 23-25, 1998.

[9] Milhorn, Richard L., "The History and Future of San Joaquin Valley Unified Air Pollution Control District Alternative Fueled Vehicle Programs," Conference on LNG: Prospecting Downstream Markets, Colorado Springs, CO, March 23-25, 1998.

[10] "The Maryland Mass Transit Administration Demonstration of Liquefied Natural Gas Buses, Final Report MTA Contract No. MTA-3-45-1, October 18, 1996. 

